\title{
In support of a wide notion of media accessibility: Access to content and access to creation
}

Pablo Romero-Fresco

Universidade de Vigo, Spain

University of Roehampton, London
Citation: Romero-Fresco, P. (2018). In support of a wide notion of media accessibility: Access to content and access to creation. Journal of Audiovisual Translation, 1(1), 187-204.

Editor(s): A. Jankowska \& J.-L. Kruger

Received: January 22, 2018

Accepted: June 30, 2018

Published: November 15, 2018

Funding: This research has been conducted within the frameworks and with the support of the EU-funded projects ILSA: Interlingual Live Subtitling for Access (2017-1-ES01-KA203-037948) and EASIT: Easy Access for Social Inclusion Training (2018-1-ES01-KA203050275) and the Spanish-government funded projects Inclusión Social, Traducción Audiovisual y Comunicación Audiovisual (FFI2016-76054-P) and EUVOS. Intangible Cultural Heritage. For a European Programme of Subtitling in Non-hegemonic Languages' (Agencia Estatal de Investigación, ref. CSO201676014-R) and the Galician-government funded project Proxecto de Excelencia 2017 Observatorio Galego de Accesibilidade aos Medios.

Copyright: @2018 Romero-Fresco. This is an open access article distributed under the terms of the Creative Commons Attribution License. This allows for unrestricted use, distribution, and reproduction in any medium, provided the original author and source are credited.

\section{Abstract}

The prevailing narrow consideration of media accessibility (MA) as concerning only persons with sensory disabilities poses a series of epistemological and terminological issues, and limits the potential of MA to instigate social change. This article supports a wider view of MA that encompasses both people with and without disabilities who need access to audiovisual content. To articulate this wide notion of MA, a distinction is made between access to content and access to creation (Dangerfield, 2017), and examples are drawn from two emerging disciplines: interlingual respeaking and accessible filmmaking (AFM). As far as access to content is concerned, interlingual respeaking can contribute to making MA more visible, forcing hearing audiences to share the same need for access as audiences with hearing loss. As for AFM, by proposing the integration of translation and accessibility as part of the filmmaking process, it provides a platform for deaf, blind and foreign audiences, as well as other groups, to join forces and increase their visibility within the film industry. However, a wide notion of MA must also include access to creation, that is, access to equipment, funding and job opportunities that can enable persons with sensory disabilities to create audiovisual products which, it is argued, can provide a more inclusive and empathetic audiovisual experience than the current model of MA.

Key words: media accessibility, access to content, access to creation, accessible filmmaking, interlingual respeaking, noncinema, disability art, disability in the arts, accessibility studies.

\footnotetext{
$凶$ P.Romero-Fresco@roehampton.ac.uk; https://orcid.org/0000-0003-2166-5792
} 


\section{Audiovisual translation and media accessibility: A housing problem}

The beginning of the $21^{\text {st }}$ century, and especially the end of its first decade, was a prolific period for research on audiovisual translation (AVT). The literature in the field included constant allusions to how this area was coming of age (Díaz Cintas, 2008), which were often followed by accounts of what makes AVT distinct. Cases were made as to why AVT deserved to have a separate room, as it were, in the translation studies (TS) building, which had become independent from linguistics and comparative literature from the late 50s (Vinay and Darbelnet, 1958; Nida, 1964; Catford, 1965; Holmes, 1988). Ten years later, and largely thanks to the unrelenting development of technology, the pervasiveness of screens and changes in viewing habits, the same AVT scholars now refer to "the incipient maturity" of AVT (Díaz-Cintas \& Neves 2015, p. 3). They wonder whether AVT has "outgrown the limits" of translation studies (TS) (p. 2) and should perhaps act as the "connecting bridge" between TS and other fields of knowledge (p. 3). Although the consolidation of AVT may still be a few steps away (the launch of this Journal of Audiovisual Translation being an essential one), it could be argued that AVT is in the process of constructing its own building within the larger TS estate, with a room devoted to media accessibility (MA). But just as TS can hardly cope with the unrelenting movement of AVT, it is worth considering whether the constant evolution of MA sits easily within the current margins of AVT.

From the very first publications about MA, this sub-area within AVT has been concerned with modalities such as subtitling for the deaf and hard of hearing (SDH) and audiodescription. This corresponds to the first of the three different accounts of MA that, according to Greco (2018), have been embraced over the years, in this case one that is specifically framed for persons with sensory disabilities. This particularist account has enabled deaf and blind user associations to acquire a leading role in the on-going battle to increase the amount and quality of access services around the world. A second account identified by Greco (2018) extends the scope of MA to both sensory and linguistic barriers, as shown in EU-funded projects such as Digital Television for All (DTV4ALL), Hybrid Broadcast Broadband for All (HBB4ALL), which involved experiments with hearing, hard-of-hearing and deaf participants. However, recent developments suggest that there may be scope for a wider, or more universalist (Greco 2018), account of MA. The EU Audiovisual Media Services Directive (2016) identifies the provision of MA as a necessary requirement not only for persons with sensory impairments but also for older people to participate and be integrated in the social and cultural life of the EU. More importantly, the latest international standard on subtitling, ISO/IEC DIS 20071-23 (International Organization for Standardization, 2018), cites as its main target users persons with hearing loss, persons who are deaf or hard of hearing, persons with learning difficulties or cognitive disabilities, persons watching a movie in a non-native language, persons who need the content to be in another language, persons who cannot hear the audio content due to environmental conditions, or circumstances where the sound is not accessible (e.g., noisy surroundings), the sound is not available (e.g., muted, no working speakers), or the sound is not appropriate (e.g., a quiet library). 
In line with the often-quoted report from Office of Communications (2015) stating that of 7.5 million users of SDH in the UK, 6 million do not have hearing loss, current legislation now seems to acknowledge that access services do not only benefit persons with sensory impairments but also the elderly, people with learning disabilities and people watching media in a foreign language, among others.

What, then, is the difference between AVT and MA? To what extent can MA be considered a room within the overall AVT building? Or are AVT modalities like subtitling, dubbing and audiodescription forms of MA? It could be argued that the boundaries between AVT and MA are somewhat blurred, and it may be problematic to consider the latter as a sub-area of the former.

Apart from these epistemological considerations, the particularist or traditional notion of MA as concerning only (or mainly) people with hearing or visual loss poses a series of problems. Firstly, from a terminological point of view, well-established labels such as subtitling for the deaf and hard of hearing, by far the most commonly used term for this subtitling modality in Europe, becomes somewhat questionable or reductionist. This has been acknowledged by Joselia Neves, author of the first PhD thesis (2005) on the subject and one of the leading scholars in the field, who is currently referring to enriched subtitles in order to "do away with much of the confusion and inaccuracy of the terminology that is presently in use, while removing the stigma of disability and allowing for developments already in progress" (2018, p. 84).

Secondly, and most importantly, this narrow view of MA limits its potential impact on areas where it should be a driving force for social change. Greco (2016) makes this point in relation to human rights, an area where most scholars and institutions do not see MA as relevant to their work. Instead, MA is referred to almost exclusively as it concerns persons with disabilities, thus overlooking the benefits it can bring about for the elderly, linguistic minorities or migrants. This is what he calls the ghetto effect, which, although in some cases it can benefit blind and deaf minorities, it often prevents MA from reaching its full potential for change. A clear example is that of South Africa. Despite the fact that the South African Constitution guarantees equal status to 11 languages and that the 1999 Broadcasting Act requires that the South African Broadcasting Corporation (SABC) "make services available to South Africans in all the official languages" (BA, 1999), $76 \%$ of SABC's programmes are in English (Dibetso \& Smith, 2012) and the SABC has adopted an English-only subtitling policy. As argued by Greco (2016), one would expect MA to be at the heart of the human rights discussion regarding language equality in South Africa, but this is not the case. $M A$ is regarded as an issue concerning deaf and blind people, as shown by the fact that the SABC only refers to subtitling in the section about persons with disabilities. In contrast, a wider notion of MA that includes persons with and without disabilities can be used as a "proactive principle for achieving human rights" (Greco, pp. 23-24), one that can help to improve literacy, promote education and increase both social cohesion and quality of life, as per the principles included in the South African constitution. 
From this wider viewpoint, MA is no longer exclusively focused on persons with sensory disabilities (or on them and foreign audiences), but it "concerns access to media products, services, and environments for all persons who cannot, or cannot properly, access them in their original form" (Greco 2016, p. 23). This wider and universalistic notion of MA is more inclusive and empathetic, as it makes everyone (whether or not they have disabilities) share the same need for accessing original content.

Yet, this is not without problems. Firstly, despite the need to widen the scope of MA to other groups, such as foreign viewers without disabilities, there are minorities with disabilities whose needs are still not being addressed. For instance, the amount and quality of SDH seems to be growing exponentially but research shows that they are normally much more suitable for hard-of-hearing viewers than for Deaf users (Romero-Fresco, 2015). The latter are often faced with an insufficient provision of sign language and with subtitles whose content, structure and speed often cause comprehension problems (Wehrmeyer, 2015). Secondly, and perhaps most importantly, most of the practical and theoretical work in MA, regardless of whether it adopts a wide or narrow notion, focuses on providing access for persons with disabilities to content made by persons without disabilities. This access to content is of course useful but, if not accompanied by other types of access, can be seen to promote a paternalistic and self-serving approach that perpetuates the agency of the able and the passive role of the disabled. A fuller and fairer view of MA must therefore include access to creation (Dangerfield, 2017), so that groups who have not traditionally been given the opportunity to create, can make audiovisual media products that will need to be accessed by all, including the able.

In an attempt to provide potential answers to the issues discussed here, the next sections focus on access to content and creation in relation to interlingual respeaking and AFM, both of which illustrate the benefits and challenges of this wide notion of MA.

\section{Access to content}

Most of the work carried out so far in the theory and practice of MA since the very first studies in the US in the 70s (Gates, 1971; Nix, 1971; Fischer, 1971) has focused on access to audiovisual content as opposed to access to creation. In the traditional and so far prevailing notion of MA, the target groups of this access have been the deaf and blind communities. Now, two emerging areas, interlingual respeaking and AFM, illustrate the need to open the scope of MA to other groups, including the elderly, children, people with learning disabilities and people without disabilities who may need linguistic access to audiovisual content in a foreign language. Here, MA includes the modalities (dubbing, interlingual subtitling, voice-over translation, etc.) as well as target users of AVT. 


\subsection{Interlingual respeaking}

Respeaking is a modality of MA concerned with the production of (live) subtitles through speech recognition. Most of the work carried out in this area has so far focused on intralingual respeaking. Research on intralingual respeaking started in 2006 (Eugeni \& Mack, 2006) and since then it has been scarce, despite the popularity and widespread use of this technique in the industry, its social impact and the increasing number of publications dealing with AVT and, more specifically, with MA. A quick search on the translation and interpreting database BITRA (https://aplicacionesua.cpd.ua.es/ tra int/usu/buscar.asp?idioma=en) shows that only $4 \%$ of the academic publications on accessibility and $0.8 \%$ of published outputs on AVT, respectively, deal with live subtitling and respeaking. In contrast, research on audiodescription, which is much less widespread than respeaking in the industry worldwide and is received by a significantly lower number of users, is more developed and features twice as many publications in BITRA. The reason for this may lie in the very few respeaking courses available at universities (no more than a handful around the world) and in the very few scholars working in this area (Romero-Fresco, 2018). Furthermore, many of these courses are embedded within large modules on subtitling for the deaf and hard of hearing (RomeroFresco, 2012b). The respeaking component is often small and taught at the end of the academic year, when students have already chosen the research topic for their dissertations. As a result of this lack of academic research and training, in countries such as the UK most subtitling companies have had no choice but to set up their own in-house respeaking programmes and scholars have had very little influence on the training and working conditions of professional respeakers, who, despite performing a task akin to simultaneous interpreting, are normally paid the same rates as subtitlers of prerecorded material.

Interlingual respeaking, a recent development in this area, offers an opportunity to learn from past mistakes. Embedded in a narrow notion of MA, intralingual respeaking was first presented to off-line subtitlers as a variation of the job they were already doing: the same product (subtitles for the deaf and hard of hearing) in a different context (live) with a different process (voice instead of typing). This ignored the facts that intralingual respoken subtitles are actually seen by viewers with and without hearing loss and that the change in process involves a significant increase in complexity that should be reflected in the salary. Interlingual respeaking presents a different situation, as it involves a type of language transfer that is as complex as (if not more than) simultaneous interpreting and is now intended, amongst others, for foreign-language viewers and people with hearing loss. It is thus an apt illustration of the wider and inclusive notion of MA described in the previous section and it provides us with the opportunity to rectify some of the mistakes made in the case of intralingual respeaking, such as the lack of research-informed training. The research conducted in EU-funded projects such as Interlingual Live Subtitling for Access (ILSA, http://www.ilsaproject.eu/), which aims to identify the skills required for this new professional profile and to create and assess the first training materials, should be useful in providing the evidence that can help to secure interpreting-like working conditions for interlingual respeakers. 
As well as opportunities, interlingual respeaking can also pose significant risks. Despite a widespread increase in subtitling quotas, the narrow view of MA as including mainly people with hearing loss has proved to cater for hard-of-hearing people more than for deaf people (Romero-Fresco 2015). The reason for this lies in the difference in reading proficiency between the two groups. Programmes with sign language are often few and far between. This means that native signers, who are a minority within the group of viewers with hearing loss, are forced to use subtitles that have been designed for hard-of-hearing viewers. These are often fast, near-verbatim subtitles that have shown to pose comprehension problems for many signers who read them in what is effectively their second language (Romero-Fresco, 2016). The Deaf minority is thus to some extent left behind for the benefit of a majority of hard-of-hearing viewers. If not implemented properly, in the wider notion of MA, which caters for both viewers with and without hearing loss, the minority left behind may be the hard of hearing. It is not hard to imagine a scenario where in an event made accessible through interlingual respeaking for an audience made up of $95 \%$ hearing people and $5 \%$ people with hearing loss, the respeaker may choose to leave out non-verbal elements such as speaker identification or sound descriptions. After all, these elements add complexity to what is already a very challenging task and would mainly (although not exclusively) benefit a small part of the audience. It is particularly important to resist this urge and ensure that wider access does not involve lower quality. As a matter of fact, if the inroads made over the past years regarding MA quality are maintained, for example when it comes to the description of non-verbal elements in the subtitles, interlingual respeaking may present an interesting opportunity to mainstream SDH to hearing audiences. Very much along the lines of Szarkowska's (2013) suggestion regarding interlingual SDH for film, it is worth fighting for a provision of interlingual respoken subtitles that caters by default for people with hearing loss. After all, the description of non-verbal elements in the subtitles is unlikely to bother hearing audiences, especially if it is presented as an intrinsic element of this new form of access, whereas its absence is bound to have a negative impact on comprehension by people with hearing loss.

Interlingual respeaking is thus a new and unexplored area that illustrates the widening scope of MA and that affords a unique opportunity to mainstream MA, to make it more inclusive and, especially, more empathetic. Hearing audiences will find it easier to put themselves in the shoes of viewers with hearing loss if they share their need for access and if this access can only be obtained through subtitles that were initially designed for deaf and hard-of-hearing people.

\subsection{Accessible Filmmaking}

AFM may be defined as the consideration of accessibility during the production of audiovisual media (through the collaboration between the creative team and the accessibility experts, including the translator) in order to provide access to content for people that cannot, or cannot properly, access it in its original form. If presented within a traditional or narrow notion of MA, this definition would need to add the word translation ("the consideration of translation 
and accessibility") and to make it clear that the target users are also those excluded for linguistic reasons. Instead, the wider perspective adopted by AFM encompasses traditional AVT modalities such as dubbing, voice-over and interlingual subtitling, as well as their respective audiences. AFM is thus in line with the aforementioned universalist account of MA and with the notion of accessibility studies proposed by Greco (2018).

As stated in an early article on AFM (Romero-Fresco, 2013), one of the aims of AFM is to address the long-standing gap between film(making) and accessibility/translation in terms of research, training and professional practice, or, perhaps more specifically, the unequal relationship between these two areas, i.e. the invisibility of translation/accessibility within the film industry. History shows that this has not always been the case. AVT is much less visible now than when it was first used at the beginning of the 20th century. Back then, even before sound was introduced in cinema, when the intertitles used in silent film had to be translated, translation was included within the postproduction stage and it was thus part of the filmmaking process. The production of the first talkies brought about the first unsuccessful attempts at dubbing and subtitling, and subsequently, a new solution: the so-called multiple-language versions (Vincendeau, 1999), also known as multilinguals or foreign language versions (Ďurovičová, 1992). Films were made and remade in two or three languages by the same director and sometimes in up to fourteen languages with a different director for each language version. The cast could remain the same or change depending on the films and the number of versions to be produced (Vincendeau, 1999). Translation was then at the very core of the production process. However, once dubbing and subtitling techniques improved, studios opted for these modes, which would reduce the cost of their translations to some $10 \%$ of the film budget (Romero-Fresco, forthcoming). Increasingly outsourced and unsupervised by filmmakers, translations lost their status as part of the filmmaking process and became part of the distribution process, as is the case now. The divorce between film and translation/accessibility was consummated and it is now visible in training, research and professional practice.

But how is it possible that MA, being as prominent as it is in society (evidenced in legislation, parliamentary debates and public opinion), is still considered a mere footnote in the film industry? One of the reasons may be the traditional conception of MA as a sub-area within AVT challenged in this article, which has had a negative impact on its visibility. Let us take the example of the UK, arguably one of the leading countries in the world when it comes to MA. User associations such as Action on Hearing Loss and the Royal National Institute for the Blind regularly contribute to (and shape) public debate; the governmental regulator Ofcom sets high quotas for access services on TV (100\% subtitling for the past three years) and assesses their quality (Romero-Fresco, 2016) and even Deaf viewers are to some extent catered for with programmes presented in sign language. After a long and successful campaign launched in 2017, Action on Hearing Loss managed to persuade the Parliament to discuss the need to introduce subtitling for video-on-demand content and to draft legislation that can force broadcasters to provide this service. MA rides the wave of political correctness and equal rights and is a key issue in society. However, when it comes to cinema, the situation is very different. Accessibility is still not visible within the British film industry, 
where it remains a side issue, tackled at the end of the process, outside the control of the filmmaker, in a short period of time and for very little remuneration. As a tentative reason, it may be possible to argue that the same ghetto effect that has helped deaf and blind lobbies achieve progress and improvement within a narrow conceptualisation of MA has also singled out these groups as a minority in the eyes of the film industry.

Why not then widen the concept of MA to include, and even go beyond, AVT and thus have blind and deaf audiences join forces with foreign viewers and other audiences? Currently, not even the link between deaf/blind and foreign viewers is being made. Yet, even though key conferences on MA such as the annual UK Council of the Deaf do not mention translation, foreign viewers are the main consumers of SDH, so all groups are in the same boat. Strengthening the link between these audiences would be a win-win scenario. Foreign viewers can benefit from the legitimacy and impact obtained by MA through legislation and human rights debates, whereas the traditional groups included within MA (deaf and blind) will finally enlarge their size and get the strength in numbers that they need. As shown by recent research (Romero-Fresco, forthcoming), more than half of the revenue obtained by the top-grossing films from the beginning of the $21^{\text {st }}$ century comes from foreign and accessible versions. In other words, we are no longer referring to a minority, but to the lion's share of the audience.

Film production companies such as Archer's Mark have embraced this inclusive AFM model. They are now implementing it in all their films and they have been involved in the production of the Accessible Filmmaking Guide (Romero-Fresco \& Fryer 2018), published by the BFI. Production and localisation managers at Netflix have asked for this guide, as they are in an ideal position to apply it: a) they used Joining the Dots (Romero-Fresco, 2012a) - a short documentary about blindness made as per the AFM model - as a means to raise awareness within the company about the essential role played by accessibility; b) most of their profit comes from the translated versions of the films they host; and c) they engage in both film production and film translation/accessibility, so they can easily integrate the latter within the former. A prime example of this is the award-winning documentary Notes on Blindness (Spinney \& Middleton, 2016). Produced by Archer's Mark and acquired by Netflix, it included translation and accessibility from its inception and has been hailed by the Guardian (Philips, 2016) for its beauty, thoughtfulness and accessibility. Indeed, the films that are adopting the AFM model are becoming flagships for a new inclusive and collaborative approach to accessibility, which helps their promotion and distribution. This is the case for Xmile (Font, 2016), the first fully accessible Spanish short film made according to the principles of AFM, which was presented and discussed at the Spanish Senate as part of an ongoing campaign to include AFM in the Spanish legislation on MA. Xmile's implementation of the AFM model involved the participation of consultants with sensory disabilities. This has also been envisaged for Archer's Mark's forthcoming production Chaplin (Spinney \& Middleton, 2019), which contributes further to increasing the visibility of accessibility and its integration as part of the production process ${ }^{i}$. 
Interestingly, AFM can also be regarded as part of a wider movement aiming to integrate translation and accessibility as part of the artistic creation process. The theatre is proving particularly active in this regard, with examples such as The Gift, a play produced by the professional Northern Irish children's touring theatre company Cahoots NI in 2015 (Maguire, 2015). With the help of the researcher Tom Maguire, the production of the play included aspects of universal design early on in the process in order to ensure that spectators with visual impairment were as integrated in the play as sighted spectators.

However, even if in some films and theatre plays this new approach manages to replace the industrialised model that relegates translation and accessibility to an afterthought in the creative industry, it would be an error to think that a full integration of accessibility within the production process is the ideal end. This is only part of the story. It is a very positive step forward, but it relates only to access (for everyone) to content (made by some, but mostly by the able). Access to creation is still to be addressed, and with it, access to funding and equipment.

\section{Access to creation}

In the Accessible Filmmaking Project, funded by the British Film Institute (BFI) and the UK-based deafblind charity Sense (Dangerfield, 2016), filmmaker and researcher Kate Dangerfield set out to make a documentary about deafblindness based on a series of filmmaking workshops that she delivered at Sense in 2016 and 2017. The plan was to involve the deafblind participants in the provision of accessibility for the film (access to content), but it soon became clear to her that the participants needed to tell their own stories, thus becoming co-directors of the film. This revealed some of the many obstacles faced by people with disabilities when they try to access (audiovisual) creation. Figure 1 sums up the different types of access involved in this process:

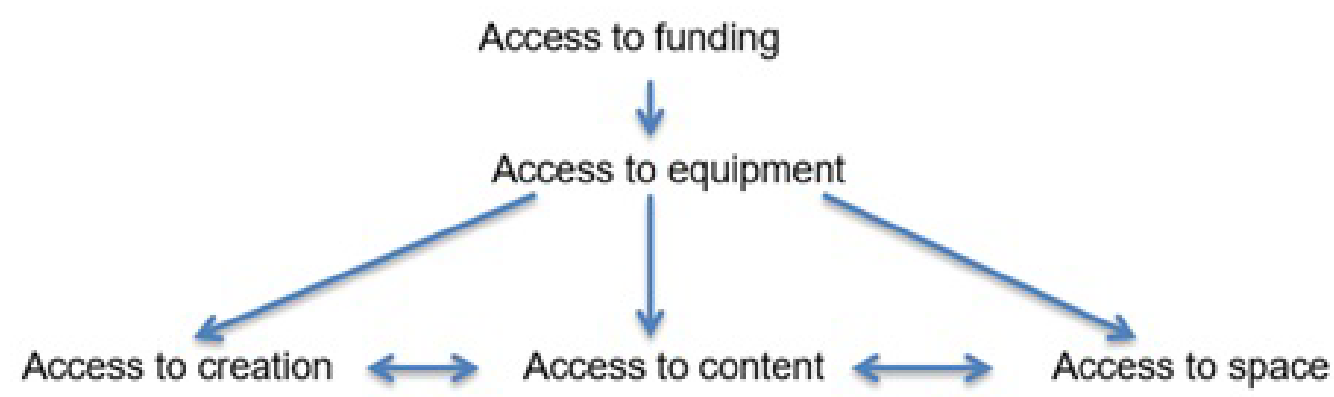

Figure 1. The different types of access involved in AFM (Dangerfield, 2017).

Many of these obstacles were overcome with special equipment and assistive technology that made it possible to attach cameras to the bodies or the wheelchairs of the deafblind participants. The resulting documentary, mostly filmed in first person point of view, is an inclusive and innovative piece of filmmaking that brings people without disabilities closer to the experience of persons 
with disabilities, and that replaces the ocularcentric focus of contemporary filmmaking (Elsaesser \& Hagener, 2010) with a more haptic approach. After all, touch is the most important sense for many deafblind people and this may well be regarded as a cinema of the senses (Laine, 2015), as well as a new approach to filmmaking that taps into current debates on the democratisation of cinema and especially the birth of the so-called non-cinema (Brown, 2016a).

The notion of non-cinema draws on movements such as, on the one hand, Third Cinema (Getino \& Solanas, 1969), which rejects both the bourgeois values of the First Cinema made in Hollywood and the individualism of the Second Cinema (European art film) in favour of collective productions aiming at revolutionary activism, and, on the other hand, Guerrilla Filmmaking (Lee, 1987), which is characterised by low budgets, minimal crews, simple props and real locations without filming permits. Non-cinema combines some of the political and financial aspects of Third Cinema and Guerrilla Filmmaking but also adds its own idiosyncratic nature, tinged with ethical implications. Brown (2018) argues that the future of cinema is not to be found in the centre but at the margins: overlooked, underfunded and not considered as cinema by distributors, exhibitors and audiences. Non-cinema refers to digital films made in an underground capacity, defying film councils and classification boards, without access to good acting, good lighting and theatrical distribution, and often engaging with the "un-, under- or even mis-represented in mainstream media, including the plight of racial, sexual and other minorities across a variety of contexts" (Brown, 2016a). Non-cinema asks us to engage politically and ethically with digital cinema. It is, as Brown (2016b, pp. 104-105) puts it, "politically imperfect cinema for the digital age" that proposes "the inclusion of the overlooked and the dispossessed, and of the darkness that necessarily accompanies the light". Non-cinema asks us not to be detached observers of the world, but to become participants therewith, also suggesting that there is more reality than what cinema wants to show us.

Kate Dangerfield's participative documentary can thus be considered an example of non-cinema, one that has been shot digitally and with a minimal budget by people from the un(der)-represented community of the deafblind, who show us a point of view/perspective of disability that suggests that there is more reality to it than what mainstream cinema has shown us. The film challenges people without disabilities to access this new reality. Needless to say, this documentary also involves the integration of translation and accessibility as part of the filmmaking process, but at this point we are no longer referring only to a wider idea of access to content, but to a freer notion of access to creation.

Interestingly, the transition of accessibility from being a footnote at the end of film production concerning only deaf and blind audiences to being considered, as per the principles of AFM, a) an integral part of production concerning all audiences (access to content) and even b) a proactive principle for creation (access to creation) is not happening only in film. Other arts such as painting and especially theatre illustrate this trend. In the theatre, perhaps more common than accessible 
theatre-making is the notion of integrated access, which, in Fryer's (2018) view and as regards AD, is being used as an umbrella term to cover the following five aspects:

That it be non-neutral (creative and /or subjective); that it be collaborative so as to reflect the director's vision (auteur); that it is considered a priori; and, that it be open and inclusive, available to be heard by all.

Fryer (2018) points out that integrated theatre AD has its risks (for instance, "sounding like stage directions without reflecting the full visual nuances of the final production"), but this can be mitigated by ensuring two-way communication between the describer(s) and the creative team. The final words of her article sum up the main advantages of integrated AD for theatre and can be largely applied to AFM:

By being conceived from the start with the sanction and full participation of the originating artists, integrated $A D$ demonstrates a commitment to access on the part of the creator(s). The advantage for the users is that $A D$ is part of the weft of the piece and will be available at every performance. It is unlikely, for example, to be dropped if budgets shrink. It has the added advantage of raising the profile of $A D$ with the wider audience and the performers. The extent of integration may vary, but at the very least an integrated approach carries with it a seal of approval in the sense that the AD users know that the director, and possibly the actors too, have sanctioned what the describer says. Perhaps it is time for this form of accessible theatre-making to become the primary approach to $A D$, so that $A D$ it is thought about from the start, and is an integral part of every production.

An interesting example of accessible theatre-making or integrated access for theatre is that of Club der Dickköpfe und Besserwisser (Kramer, Jesse \& Grün, 2016), a play that was made accessible from inception by the theatre group Theater Kirschrot with the help of students from the University of Hildesheim. It features deaf and hearing children and the languages used on stage (by the actors and in the projected videos) are German in spoken and written form and German Sign Language. In the play, the surtitles used on stage are not only a means of translation (for German Sign Language or spoken German) that is needed by the entire audience (a wider notion of access) but also a character that interacts with the actors on stage or with the children in the videos, that is, an aesthetic element of the play. Club der Dickköpfe und Besserwisser is thus another example of accessible theatre making as far as access to content is concerned and the fact that it involves deaf children in the production also makes it an example of access to creation.

At this point, a further distinction must be made between disability art and disability in the arts. First coined in 1986, disability art referred originally to art made by people with disabilities which tackles disability (Sutherland, 2008). Following the Disability Discrimination Act of 1995 in the UK and the revised Disability Discrimination Act in 2004, it was recognized that society as a whole and not just people with disabilities needed to support the movement. In other words, disability art came to refer to art that takes on disability as its theme (i.e. exploring the conceptual ideas and physical 
realities of what is to be disabled) but that does not necessarily have to be made by people with disabilities. In contrast, disability in the arts refers to art that involves the active participation or representation of people with disabilities in the arts, whether or not the theme is disability. Currently, the growing visibility of disability and accessibility in the arts falls mainly within the category of disability art. In other words, these are films (Joining the Dots, Romero-Fresco, 2012a; Notes on Blindness, Spinney \& Middleton, 2016) and film festivals (Superfest International Disability Film Festival in San Francisco, ReelAbilities in New York, Breaking Down Barriers Film Festival in Moscow, Look\&Roll Film Festival in Basel) that may or may not involve artists with disabilities, but which deal with disability as a theme. Although all these initiatives are a tremendous step forward and an inspiration for the work to come, there is still a clear need for more disability in the arts, that is, for the normalised participation of people with disabilities in the creation of art that does not necessarily deal with disability as a theme. This is the case of Vital Xposure, a theatre company led by the disabled artist Julie McNamara that makes productions geared towards social engagement while ensuring quality training, work experiences for talented artists with disabilities and integrated access. They do not necessarily deal with disability as a theme and can thus be considered as an example of disability in the arts.

Unfortunately, the film industry is lagging behind. Research by the Office of National Statistics $(\mathrm{BFI}, 2015)$ in the UK shows that $14 \%$ of employed people aged 16-64 consider themselves disabled, and yet according to the 2012 Creative Skillset employment census, only $0.3 \%$ of the total film workforce are disabled ( $0.2 \%$ in production, $0.1 \%$ in exhibition and none in distribution). This also applies to other under-represented groups. As shown by a study conducted in 2012 (BFl, 2015), professionals from Black, Asian and minority ethnic backgrounds only made up 5.3\% of the film production workforce, $3.4 \%$ of the film distribution workforce and $4.5 \%$ of the film exhibition workforce. In order to tackle this, the BFI has made it one of its key priorities to develop a new agenda on diversity. Just as accessibility has gone in the area of MA from referring to deaf and blind people to including the fully sighted and hearing users of translation and then even the more general view of universal access provided by accessibility studies (Greco 2018), the BFI has replaced its focus on accessibility for one on diversity, thus including a wider range of under-represented groups, with a focus on disability, gender, race, age, sexual orientation and socio-economic condition. The BFI regards diversity as the recognition and acknowledgement of the quality and value of difference, and seeks to reflect the public in the films they fund, the programmes they support, the audiences who watch them and the filmmakers, actors and crews who make them (BFI, 2016). Applicants for funding to the BFI are asked to demonstrate how their project will contribute to reducing under-representation in relation to at least one of the four themes in the BFI Diversity Standards (BFI, 2016): on-screen representation (diversity in the story), project leadership and creative practitioners (diversity in the creative team), industry access and opportunities (work experience and development opportunities) and audience development (reaching a more diverse audience). Of the four themes, and as far as disability is concerned, the last one is directly related to the access-to-content dimension of AFM and the first two may be included within the access-to-creation dimension: diversity in the story would be linked to disability art and 
diversity in the creative team to disability in the arts. The BFI's new focus on diversity thus seems to be in line with the wide notion of access proposed in this article.

\section{Final thoughts}

Neither the current and prevailing narrow consideration of MA as concerning only people with sensory impairments nor one that extends its scope to foreign audiences seem to be a true reflection of who is using these access services or who is concerned by the new legislation in this area. Based on the idea of accessibility as an instrument for the human rights of all, this article supports a wider view of MA, one that encompasses both people with disabilities and people without disabilities who may need access to audiovisual content. This shift involves not only epistemological (is MA part of AVT or vice versa?) and terminological considerations (is it accurate to refer to SDH when this service is mainly consumed by hearing viewers?) that merit their own separate discussions, but it can also help to unleash the enormous potential that MA has for social change. In order to articulate this wider notion of MA, it is useful to make a distinction between access to content and access to creation and to dwell on two emerging disciplines: interlingual respeaking and AFM.

MA has traditionally focused, almost exclusively, on access to content. This is the case for interlingual respeaking, a development of intralingual respeaking whose importance lies precisely in the fact that it can provide access to both people with and without hearing loss. As a clear illustration of a wide notion of MA, it presents both challenges and opportunities. Now that it is still being studied and tested, it is essential to ensure that its complexity is acknowledged as far as salary and working conditions are concerned (which has not been the case for intralingual respeaking) and that it does not only cater for a majority of hearing users who may need this service, leaving behind a minority of people with hearing loss who need interlingual respoken subtitles to adhere to SDH standards. As a matter of fact, interlingual respeaking presents a unique opportunity to mainstream MA, ensuring that, when accessing live productions in a foreign language, hearing audiences will always receive, by default, subtitles for people with hearing loss. This can make MA more visible, inclusive and empathetic, as it forces hearing audiences to share the same need for access as audiences with hearing loss and to resort to subtitles that are specifically designed for the latter.

The wide notion of access to content presented here is also at the core of AFM, which envisages the integration of accessibility (including translation) into the filmmaking process. AFM can help to bridge the long-standing gap between film and AVT/MA and to increase the visibility of the latter within the former. This has been illustrated here with regard to two key groups of viewers: persons with sensory disabilities and foreign viewers. By joining forces with the deaf and blind communities, foreign-language audiences benefit from the social impact of MA, its presence in legislation, etc., whereas persons with sensory disabilities obtain from the foreign-language users the strength in numbers that can turn what has traditionally been a minority group into a majority. 
However, widening the scope of MA also means going beyond providing access to content that is typically made by people without disabilities and expanding this to access to creation. Some of the most innovative projects that are adopting the AFM model are using this approach as a platform to enable participants with sensory disabilities to take responsibility for the creation of audiovisual products. In some of these cases, the resulting films are both innovative and unique, and fall within the emerging trend of so-called non-cinema (Brown, 2018). They are films that defy traditional production and distribution routes, and that challenge us to engage with the un- or underrepresented and with a reality that has so far been absent from cinema or shown only, second hand, by filmmakers without disabilities. In this battle to obtain access to creation, persons with disabilities may want to adopt an even wider approach to MA and adhere to the idea of diversity promoted by other under-represented groups, such as Black, Asian and minority ethnic backgrounds, the LGBTQ community and women. As shown by Kate Dangerfield's project, the above-mentioned figures from the Creative Skillset and a recent article published on the Guardian entitled "Isn't it time disabled actors and directors were allowed to make their own films?" (Edgar, 2018), this fight for access to creation is likely to be long and full of obstacles to overcome, namely access to (assistive) technology, funding and the professional market, which in itself requires a profound change in attitudes and a set of proactive policies. Finally, it is important to bear in mind that even if access to creation is obtained, the ultimate goal should go a bit further and ensure that artists with disabilities are not only able to make films about their group/plight (disability art), but about any other topic they choose to tackle (normalised disability in the arts).

Despite the prevalence of the industrialised model that adopts a narrow view of MA, relegating it to the end of the process and keeping its (deaf and blind) users away from creation, there are now enough examples in film and theatre to show that an alternative, wider, more inclusive and more integrated form of MA is possible. This is the rationale behind the new Galician Observatory for Media Accessibility (GALMA), a research group based at Universidade de Vigo (Spain) that aims to operationalise this wider and universalist notion of MA at an international level through collaboration with a wide network of like-minded researchers. This is done through research projects (at transatlantic, EU and national levels, and dealing, for example, with AFM or interlingual respeaking), training courses and professional work, mostly applied to films and other audiovisual productions that choose to integrate accessibility as part of the production process or to enable access to creation. The nature of the work carried out within GALMA leads to one final reflection that may be applicable to similar groups. Although GALMA is based at the Faculty of Translation at Universidade de Vigo and some of the researchers are translation and interpreting scholars, others have a different background (philosophy, psychology, film, etc.), which is reflected in the heterogenous nature of the work carried out within the observatory. While this makes the research varied and vibrant, it also makes it difficult to classify according to traditional areas, for example, when applying for funding. In any case, the wide notion of MA supported here is what binds everything and everyone together in GALMA, which begs the question of whether, from a theoretical point of view, it still makes sense to draw only on the theoretical tenets 
of translation studies (or even AVT studies) instead of looking elsewhere at the potential development of accessibility studies (Greco, 2018).

To conclude, the famous film critic Roger Ebert once said: "We all are born with a certain package. We are who we are: where we were born, who we were born as, how we were raised. We're kind of stuck inside that person, and the purpose of civilization and growth is to be able to reach out and empathize a little bit with other people. And for me, the movies are like a machine that generates empathy. It lets you understand a little bit more about different hopes, aspirations, dreams and fears. It helps us to identify with the people who are sharing this journey with us." (Collette, 2014)

As is the case with many other statements about film, these words refer to original films and original audiences. Translated or accessible versions produced over three days for little remuneration and without access to the creative team cannot always manage to convey the original vision of the filmmaker, or indeed the same degree of empathy. The wider notion of MA supported in this paper may just be one of the missing elements that can help movies unleash their potential for empathy, not only for original viewers but also for those of the translated and accessible versions, so that we can find it easier to identify with the people who are sharing this journey with us.

\section{Acknowledgements}

This paper is an extended and adapted version of the plenary "Widening the scope of media accessibility", presented at the Intermedia 2017 - International Conference on Audiovisual Translation in Poznan (Poland) on 25 September 2017. I am indebted to the organisers of the conference for their invitation and to my colleagues at GALMA, with special mention to Kate Dangerfield and Gian Maria Greco, for the long discussions that have led to the development of this paper.

\section{Biographical note}

Pablo Romero-Fresco, PhD, is a Ramón y Cajal grant holder at Universidade de Vigo (Spain) and Honorary Professor of Translation and Filmmaking at the University of Roehampton (London, UK). He is the editor of The Reception of Subtitles for the Deaf and Hard of Hearing in Europe (2015, Peter Lang) and the author of the books Subtitling through Speech Recognition: Respeaking (2012, Routledge) and Accessible Filmmaking: Integrating translation and accessibility into the filmmaking process (forthcoming, Routledge). His Accessible Filmmaking Guide, written with Louise Fryer, is currently being used by governments, film schools and filmmakers in several countries and he has collaborated with governments, universities, companies and user associations around the world to introduce and improve access to live events for people with hearing loss. $\mathrm{He}$ is the leader of the international research group GALMA (Galician Observatory for Media Access), for which he is currently coordinating several international projects on media accessibility 
and accessible filmmaking, including "ILSA: Interlingual Live Subtitling for Access", funded by the EU Commission. Pablo is also a filmmaker. His first documentary, Joining the Dots (2012), was used by Netflix as well as schools around Europe to raise awareness about audio description.

\section{References}

BA (1999) Broadcasting Act no. 4 of 1999, Republic of South Africa.

British Film Institute. (2015). Diversity. Our commitment to diversity. Retrieved from http://www.bfi.org.uk/about-bfi/policy-strategy/diversity

British Film Institute. (2016). Diversity standards. Retrieved from https://www.bfi.org.uk/sites/bfi.org.uk/files/downloads/bfi-diversity-standards-leaflet2016-05-11.pdf

Brown, W. (2016a, February 24). What is non-cinema? [Blog post]. Retrieved from https://euppublishingblog.com/2016/02/24/what-is-non-cinema/

Brown, W. (2016b). Non-cinema: Digital, ethics, multitude. Film-Philosophy, 20(1), 104-130.

Brown, W. (2018). Non-cinema. Global digital filmmaking and the multitude. London: Bloomsbury.

Catford, J.C. (1965). A Linguistic Theory of Translation. London: Longman.

Collette, O. (2014, January 27). Moving through empathy: On "Life Itself" [Blog post]. Retrieved from https://www.rogerebert.com/balder-and-dash/moving-through-empathy-on-life-itself

Dangerfield, K. (2016, March 31). Lights, camera, action! [Blog post]. Retrieved from https://blog.sense.org.uk/author/kdangerfield/

Dangerfield, K. (2017, September). The accessible film project. Paper presented at the Intermedia Conference in Poznań, 25 September 2017.

Díaz Cintas, J. (2008). Audiovisual translation comes of age. In D. Chiaro, C. Heiss \& C. Bucaria (Eds.), Between text and image: Updating research in screen translation (1-9). Newcastle upon Tyne: Cambridge Scholars Publishing.

Díaz Cintas, J., \& Neves, J. (2015). Taking stock of audiovisual translation. In J. Díaz Cintas \& J. Neves (Eds.), Audiovisual translation. Taking stock (1-8). Amsterdam: John Benjamins.

Dibetso, L.T., \& Smith, T. (2012). Lack of diversity (repeat). Analysis of SABC news and programming. Retrieved from

https://www.mediamonitoringafrica.org/images/uploads/SABC 2012 PDF Whole small.p df

Ďurovičová, N. (1992). Translating America: The Hollywood Multilinguals 1929-1933. In R. Altman

(Ed.), Sound theory/sound practice (139-153). New York: Routledge.

Edgar, J. (2018, February 9). Isn't it time disabled actors and directors were allowed to make their own films? The Guardian. Retrieved from

https://www.theguardian.com/film/2018/feb/09/let-disabled-actors-and-directors-maketheir-own-films-shape-of-water

Elsaesser, T., \& Hagener, M. (2010). Film theory: An introduction through the senses. New York: Routledge. 
Eugeni, C. \& Mack, G. (Eds.) (2006). New technologies in real time intralingual subtitling. Intralinea. Special issue: Respeaking. Retrieved from http://www.intralinea.it/specials/respeaking/eng open.php

Fischer, D. C. (1971). Improvement in the utilization of captioned films for the deaf (Unpublished doctoral dissertation). University of Nebraska, Dissertation Abstracts International, 1971, 32, 693A, University Microfilms No. T1-19842.

Font, M. Á. (2016). Xmile [Motion picture]. Spain: HT Producciones.

Fryer, L. (2018). Staging the audio describer: An exploration of integrated audio description. Disability Studies Quarterly, 38(3). Retrieved from http://dsq-sds.org/article/view/6490/5093

Gates, R. R. (1971). The reception of verbal information by deaf students through a television medium - a comparison of speechreading, manual communication, and reading. In Proceedings of the Convention of American Instructors of the Deaf (pp. 513-512), Little Rock.

Getino, O. \& Solanas, F. (1969). Hacia un Tercer Cine [Toward a Third Cinema]. Tricontinental, 107132.

Greco, G. M. (2016). On Accessibility as a human right, with an application to media accessibility. In A. Matamala \& P. Orero (Eds.) Researching audio description. New approaches (pp.11-33), London: Palgrave MacMillan.

Greco, G.M. (2018). The nature of accessibility studies. Journal of Audiovisual Translation, 1(1), 205232.

International Organization for Standardization (2018). Information technology - user interface component accessibility - Part 23: Guidance on the visual presentation of audio information (including captions and subtitles) (ISO/IEC DIS 20071-23: 2018). Retrieved from https://www.iso.org/standard/70722.html

Kermode, M. (2016, July 3). Notes on blindness review - seeing the light despite the darkness.

The Guardian. Retrieved from https://www.theguardian.com/film/2016/jul/03/notes-onblindness-john-hull-review-mark-kermode

Kramer, S. Jesse, M., \& Grün, K. (2016). Dickköpfe und Besserwisser.

Higson, A. \& Maltby, R. (Eds.). (1999). "Film Europe" and "Film America": Cinema, commerce and cultural exchange 1920-1939. Exeter: University of Exeter Press.

Holmes, J. S. (1988). The name and nature of translation studies. In Holmes, J.S. (Ed.), Translated! Papers on literary translation and translation studies (pp. 67-80). Amsterdam: Rodopi.

Laine, T. (2015) Bodies in pain: Emotion and the cinema of Darren Aronofsky. New York/Oxford: Berghahn Books.

Lee, S. (1987). Spike Lee's gotta have it: Inside guerrilla filmmaking. New York: Fireside Books. Maguire, T. (2015). Accessible theatre-making for spectators with visual impairment: Cahoots NI's The Gift. Ulster: Ulster University.

Neves, J. (2005). Audiovisual translation: Subtitling for the deaf and hard-of-hearing (Unpublished doctoral dissertation). University of Surrey-Roehampton: London

Neves, J. (2018). Subtitling for deaf and hard of hearing audiences (SDH). In L. Pérez-González (Ed.), The Routledge handbook of audiovisual translation (pp. 82-96), London: Routledge. 
Nida, E. (1964). Toward a science of translating. Leiden: EJ Brill.

Nix, G. W. (1971). The effects of synchronized captioning on the assimilation of vocabulary and concepts presented in a film to intermediate level deaf children (Unpublished doctoral dissertation). University of Oregon, Dissertation Abstracts International, 1972, 32, 5074

A, University Microfilms No. 72-8584.

Office of Communications. (2015). Television access services. Review of the Code and guidance. London: Ofcom.

Philips, C. (2016, June 15). Notes on blindness review: a beautiful, accessible and thoughtful one-off. The Guardian. Retrieved from https://www.theguardian.com/film/2016/jun/15/notes-onblindness-review-beautiful-accessible-thoughtful-one-off

Romero-Fresco, P. (2012a). Joining the Dots [Motion picture]. United Kingdom: Sunday Films.

Romero-Fresco, P. (2012b). Respeaking in translator training curricula: Present and future prospects. Interpreter and Translator Trainer, 6, 91-112.

Romero-Fresco, P. (2013). Accessible filmmaking: Joining the dots between audiovisual translation, accessibility and filmmaking. The Journal of Specialised Translation 20, 201-223.

Romero-Fresco, P. (Ed.). (2015). The reception of subtitles for the deaf and hard of hearing in Europe. Bern/Berlin/Bruxelles/Frankfurt am Main/New York/Oxford/Wien: Peter Lang.

Romero-Fresco, P. (2016). Accessing communication: The quality of live subtitles in the UK. Language \& Communication, 49, 56-69.

Romero-Fresco, P. (2018). Respeaking subtitling through speech recognition. In L. Pérez-González (Ed.), The Routledge Handbook of Audiovisual Translation (pp. 96-113). London: Routledge.

Romero-Fresco, P. (forthcoming). Accessible Filmmaking: Integrating translation and accessibility into the filmmaking process. London: Routledge.

Romero-Fresco, P., \& Fryer, L. (2018). The accessible filmmaking guide. London: British Film Institute. Spinney, J. \& Middleton, P. (2016). Notes on Blindness [Motion picture]. United Kingdom: Archer's Mark.

Spinney, J. \& Middleton, P. (2019). Chaplin [Motion picture]. United Kingdom: Archer's Mark.

Stone, C. (2009). Toward a deaf translation norm. Washington D.C.: Gallaudet University Press.

Sutherland, A. (2008, July 22). Disability arts chronology [Blog post]. Retrieved from https://www.disabilityartsonline.org.uk/Chronology of Disability Arts

Szarkowska, A. (2013). Towards interlingual subtitling for the deaf and the hard of hearing. Perspectives: Studies in Translatology, 21(1), 68-81.

Vinay, J.-P. \& Darbelnet, J. (1958/1995). Comparative stylistics of French and English: A methodology for translation. Amsterdam and Philadelphia: John Benjamins.

Vincendeau, G. (1999). Hollywood Babel: the coming of sound and the multiple-language version. In R. Altman (Ed.), Sound theory/sound practice (207-224 ). New York: Routledge.

Wehrmeyer, E. (2015). Comprehension of television news signed language interpreters. Interpreting, 17(2), 195-225.

'This is partly related to the Deaf translation norm (Stone 2009), an idiosyncratic translation practice that results from the increasing presence of Deaf translators and interpreters in several contexts such as websites, public services, government literature and audiovisual media. 